\title{
Nonlinear mechanical model of the shaft of a roll forming mill and parameter identification
}

\author{
Matthias Lamprecht ${ }^{1}$ (D) . Emin Koçbay ${ }^{2}$ (D) - Martin Leonhartsberger ${ }^{1}$ (D) . Yury Vetyukov ${ }^{2}$ (D) . Friedrich Bleicher ${ }^{1}$ (D)
}

Received: 17 June 2020 / Accepted: 24 November 2020 / Published online: 17 January 2021

(C) The Author(s) 2021

\begin{abstract}
Roll forming is a continuous process in which a moving metal sheet passes through numerous pairs of opposing forming rolls. The shafts of the roll forming mill are equipped with these rolls and must be set up and aligned to achieve the required final profile of the sheet. The practically relevant task of predicting the profile geometry of this incremental rolling process with varying characteristics of the metal sheet entering the mill requires an accurate description of the stiffness behavior of the shaft with rolls, which is the most compliant part of the roll forming mill. In this paper, the measured force-deflection characteristic of the shaft without rolls is compared with predictions of various theoretical models, followed by the adoption of the shear deformable beam model of the shaft with nonlinear elastic supports in the bearings. The coefficients of the cubic stiffness characteristics of the rotational springs as well as the effective length between the supports are identified based on the experimental data for the deflections, measured along the shaft for various loading levels. The theoretical predictions are obtained via the nonlinear finite element model of the shaft. The model thus provided shows high accuracy compared with the measurements. The paper's results serve as a foundation for models to predict the stiffness of shafts with rolls.
\end{abstract}

Keywords Roll forming $\cdot$ Roll forming mill $\cdot$ Parameter identification $\cdot$ Stiffness behavior $\cdot$ Mechanical model

\section{Introduction}

In roll forming, two opposing shafts with rolls, which are usually different for each forming pass, carry out the bending and determine the shape of the deformed profile [5]. The consecutively arranged forming passes incrementally form the final profile. The forming forces, which, depending on various parameters of the forming pass, vary significantly, cause deflections of the upper and lower shafts. In this paper, standard (conventional) mills, which are supported on both ends, are investigated. The stiffness of a shaft with equipped rolls depends on many parameters and is different for each forming pass. The

Matthias Lamprecht

matthias.lamprecht@tuwien.ac.at

Emin Koçbay

emin.kocbay@tuwien.ac.at

1 IFT - Institute of Production Engineering and Photonic Technologies, Vienna University of Technology, Getreidemarkt 9, 1060 Vienna, Austria

2 Institute of Mechanics and Mechatronics, Vienna University of Technology, Getreidemarkt 9, 1060, Vienna, Austria deflections of the shafts, which are caused by the forming forces, have to be compensated for by adjusting them.

Although rolling is a very different process to roll forming, the necessity of accounting for the shaft distortion is the same and some approaches exist in the field of rolling. In the case of rolling thick sheets, special roll mills such as continuous variable crown (CVC) and pair cross (PC) mills equipped with roll shifting, roll crossing, and work roll bending exist as means to account for shaft distortion $[3,4,15]$. However, in the case of rolling thin sheets, this problem is pronounced and amplified due to the work rolls having contact to each other on the edges. For this case, an advantageous constructive setup of the mill is not sufficient and the resulting (non-uniform) distribution of the contact pressure must be accounted by other means. In [6], the authors propose a sophisticated beam model in order to simulate the process of rolling sheet metals and research the effect of rolling parameters on rolling of thin sheet during work roll edge contact. The introduced model takes several effects (deformation due to bending, deformation due to shear, contact etc.) into account and is implemented by means of the influence function method. Although investigations regarding the roll mill or shaft distortion have been carried out and exist in the field of rolling, it is still 
not common in the field of roll forming. Within the scope of this paper, a nonlinear model for the shaft of a roll forming mill is implemented and its parameters are identified by the use of physical experiments or measurements.

According to Bhattacharyya et al. [2], the forming force can be divided into three main components: the load that is due to transverse folding and associated stretching, the load that is due to longitudinal reverse bending after the deformed strip reaches the next roll, and the clamping or "bite" load. Inertial forces can be neglected because of the low feed rate of the sheet and the resulting low angular velocities of the shafts [9]. If eccentricity of the rolls on the shaft and the out-of-roundness of the rolls are neglected, the forming process can be described as a steady-state condition [8]. For new profile cross-sections, the alignment of the shafts of the forming mills, especially in the vertical direction, takes up to $16 \mathrm{~h}$. Understanding and being able to describe the stiffness behavior of the shafts with equipped rolls, in combination with prior knowledge of the emerging forming forces, would lead to a reduction of the set-up time, because the necessary infeeding of the shafts against each other can be predicted in advance. In addition, this would show the way to a semi-automated alignment of the shafts. In other studies on numerical roll forming, the rolls are considered to be rigid bodies that are fixed in space [7, 10$12,14,16]$. As a consequence, the compliance of the tool is neglected. Abeyrathna et al. [1] take the stiffness of the tool into account by using one linear spring for each upper rollset. This means that the upper rolls of each forming pass have one degree of freedom in the vertical direction. Traub et al. [13] also use one linear spring in the vertical direction for each upper roll-set, as well as one linear spring, acting in the horizontal direction, for each side roll. Müller [9] compares the normal forces of experimental data with those acquired by means of numerical simulation for a profile with a U-shaped cross-section where the rolls are rigid and fixed in space. The force level of the numerical simulation is a few times higher than the force level in the experiments. Subsequently, he uses a simple linear spring to account for the stiffness of the tool. All these approaches neglect both the nonlinear bending behavior and the bending line. The changing contact conditions of the rolls in dependence of the load can be predicted only with a more complex representation of the stiffness behavior of the shaft.

This paper investigates the stiffness behavior of the shaft without rolls and develops suitable shear deformable beam models. In order to validate the accuracy of the developed models, experiments are carried out. To the best of the authors' knowledge, research solely committed to modeling the shaft is still a lacuna. The paper considers itself exclusively with the shaft, leaving the rolls out of the picture. The shaft is viewed as a fully linear Timoshenko beam. For reasons of simplicity and clarity, the model presented here neglects the key connection and views the shaft as a stepped beam without a key or the groove for it. The radial load is modeled as a single radial force. The modeling of the support conditions proves to be particularly challenging. Different approaches are tested, such as ideal supports versus elastic supports in the form of springs. Since the parameters of the supports are not known beforehand, we carry out a parameter identification by using experimental data as a reference. Ultimately, a linear beam model in which the supports are modeled in terms of a linear (radial) spring acting on one boundary of the beam and a linear (radial) and a cubic (rotational) spring acting on the other boundary proves to be the most successful option. Additionally to the beam model, a 3D continuum FEM model in ANSYS was set up in order to gain a deeper understand of the occurring nonlinear effects.

\section{Experimental structure and measurements used for future identification}

\subsection{Standard roll forming mill}

This paper investigates the stiffness behavior of the shafts and the forming stands of a standard (conventional) mill. The three main components of the forming mill are the drive-side stand, the operator-side stand, and the shaft (see Fig. 1). Among these three components, the shaft is the most compliant one.

The drive-side faces the drivetrain, and during production, at least one shaft of each forming pass is usually connected to the drivetrain. The operator-side stand can be removed easily to equip the shafts with rolls (which are not displayed in Fig. 1). Both stands are positioned on the mill bed with a feather key, and the mill bed mountings (1) are fastened to it with screws. To increase the rigidity of the forming stands and to mount some additional parts, the head 4 and the respective mill bed mounting can be connected with a supporting plate (not mounted in Fig. 1). To measure the vertical load during the experiments, one force sensor 8 per forming stand is installed. The vertical positioning of the upper and lower shafts 7 is done with the help of a manual spindle drive 6 connected with the corresponding bearing pedestal. Normally, the movement of the drive-side pedestal 2 and the movement of the operator-side pedestal 3 are synchronized with a connector tube 9 . The bearing pedestals are guided along the guide posts (5) with a clearance that, due to manufacturing tolerances, ranges between 0.1 and $0.2 \mathrm{~mm}$. The clearance between the bearing pedestals and the guide posts for the drive-side as well as the operator-side is close to the upper tolerance limit of $0.2 \mathrm{~mm}$, verified by measurements. 


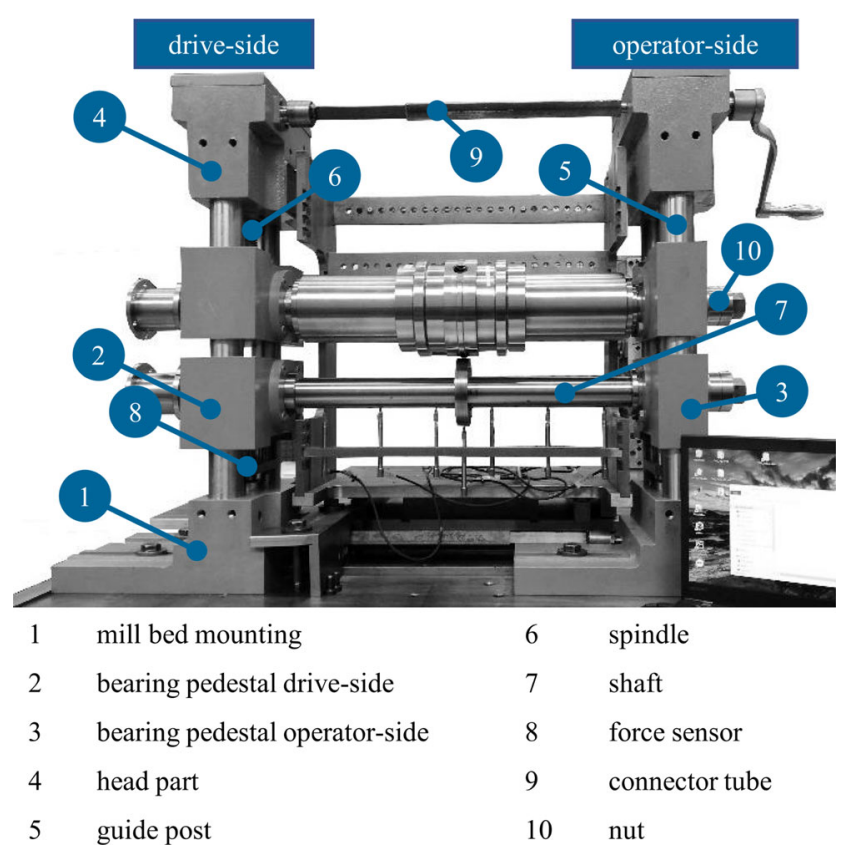

Fig. 1 Components of the roll forming mill

\subsection{Shaft}

As previously mentioned, the shaft is the most compliant component of the roll forming mill. Figure 2 shows only the lower shaft, on which the force sensors are placed. All parts of the assembly are just represented in a simplified way. The supports and pedestals of the upper shaft are identical.

The drivetrain can be connected at (1). The shaft is three-way supported by (from left to right) one angular contact ball bearing 2 , one needle roller bearing 3 in the bearing pedestal on the drive-side (6), and another identical needle roller bearing in the bearing pedestal on the operator-side (7). Due to the bearing arrangement, the drive-side pedestal initiates a relatively high moment into

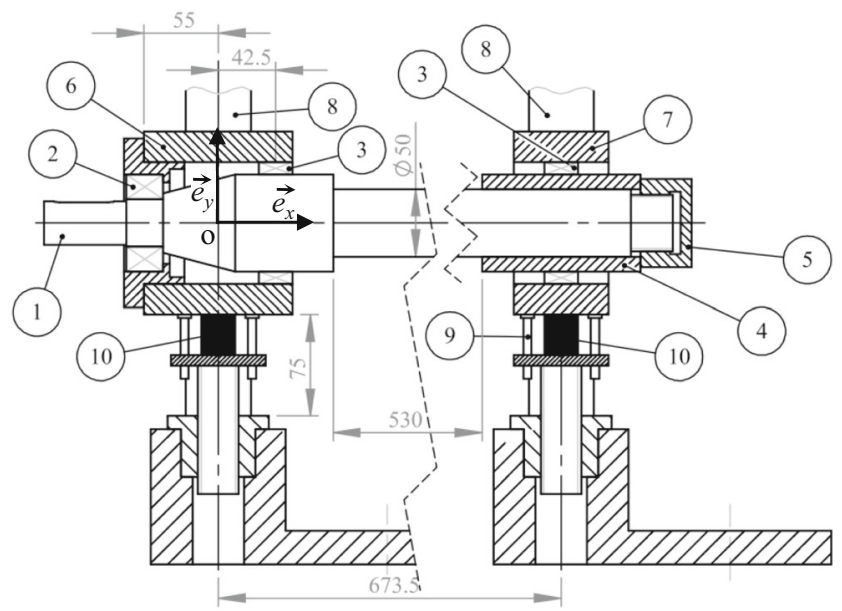

Fig. 2 Structure and supports of the shaft

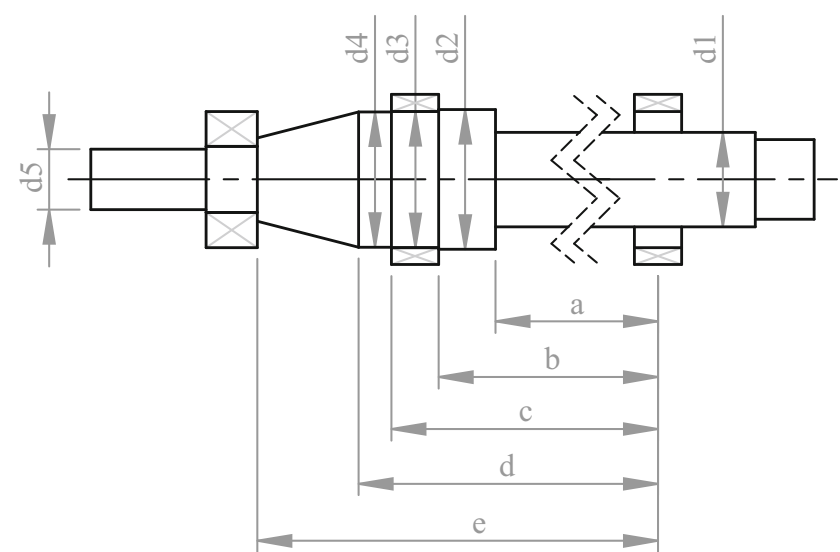

Fig. 3 Dimensions of the shaft

the guide posts 8. By contrast, the force application point of the needle roller bearing on the operator-side lies on the plane of the axis of the guide posts so that, in the ideal case, no moment is initiated there. In general, the rolls are positioned between the shaft shoulder on the drive-side and the bearing sleeve (4); by tightening the nut (5), the rolls are pretensioned, which also increases the stiffness. Here no rolls are used, so no pretension force can be applied. Dowel pins 9 keep the force sensor 10 aligned horizontally and prevent the rotation of the mounting plate when the spindle drive is in use. The diameter of the shaft is a function of the coordinate $x$. The geometrical properties of Table 1 refer to Fig. 3 (as well as Fig. 8). As for the material parameters in Table 1, $E$ is the Young's modulus, $G$ is the shear modulus, and $\kappa_{\mathrm{S}}$ is the shear deflection constant for a circular-shaped cross-section.

\subsection{Sensor application and data acquisition}

The data for validating the model are generated on the original shaft. Axial probes on discrete positions (shown in Fig. 4) give the deflection of the shaft when it is forced to bend. For this purpose, LVDT sensors (TESA GT62 DC) are used.

Table 1 Geometry and material parameters of the shaft

\begin{tabular}{ll}
\hline$d_{1}=50 \mathrm{~mm}$ & $a=588.5 \mathrm{~mm}$ \\
$d_{2}=68 \mathrm{~mm}$ & $b=603.5 \mathrm{~mm}$ \\
$d_{3}=65 \mathrm{~mm}$ & $c=648.4 \mathrm{~mm}$ \\
$d_{4}=64.8 \mathrm{~mm}$ & $d=663 \mathrm{~mm}$ \\
$d_{5}=35 \mathrm{~mm}$ & $e=714.5 \mathrm{~mm}$ \\
$\alpha=22 \mathrm{deg}$ & $f=350 \mathrm{~mm}$ \\
$E=210000 \frac{\mathrm{N}}{\mathrm{mm}^{2}}$ & $l_{1}=631 \mathrm{~mm}$ \\
$G=79300 \frac{\mathrm{N}}{\mathrm{mm}^{2}}$ & $l_{2}=97 \mathrm{~mm}$ \\
$\kappa_{\mathrm{S}}=0.9$ & $l=728 \mathrm{~mm}$ \\
\hline
\end{tabular}




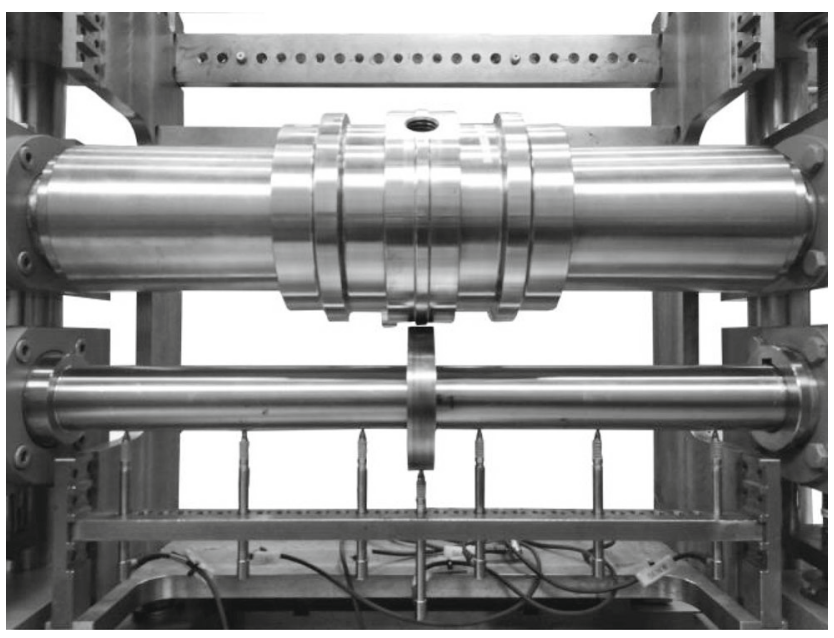

Fig. 4 Experimental setup

The piezo-based force sensors (Kistler 9333A), which are represented as 10 in Fig. 2, measure the induced load on the drive-side and on the operator-side. All data are acquired by means of a DAQ system (National Instruments 9205). An application coded in Matlab is used for calculations and storing data. The load, employed by a single force, is applied by manually infeeding the upper shaft against the lower shaft. The force is transmitted to the lower shaft via a special roll setup on the upper shaft (Fig. 4). The data acquisition rate is $50 \mathrm{~Hz}$ for all measurements.

The deflection of each bearing pedestal is measured simultaneously so as to compensate for the deflection of the pedestals and get the deflection of the shaft in its "pure" form. This is done by repeating the experiment and measuring the deflections of the corners of the bearing pedestals and the applied forces. These four datasets, detected on each of the lower bearing pedestals, are used to calculate an arithmetic mean of the vertical deflection occurring in the experiment on both the operator- and driveside. The calculated values are then used to compensate the occurring deflections of the shaft according to their position in the experiment between the forming stands. The experiments to gather this data are also repeated five times and the arithmetic mean of these measurements is used for compensation later on. The information gathered about the deflections induced by known force levels is used to compare the models with the observations made in reality (Figs. 11, 5, 18, and 16). In all following measurement data, the deflection of the pedestals is already accounted for. To guarantee precision, every experiment is repeated several times and measured outliers are not considered. Due to small remaining deviations between repeated measurements, a mean value of these measurements is used for all further considerations.

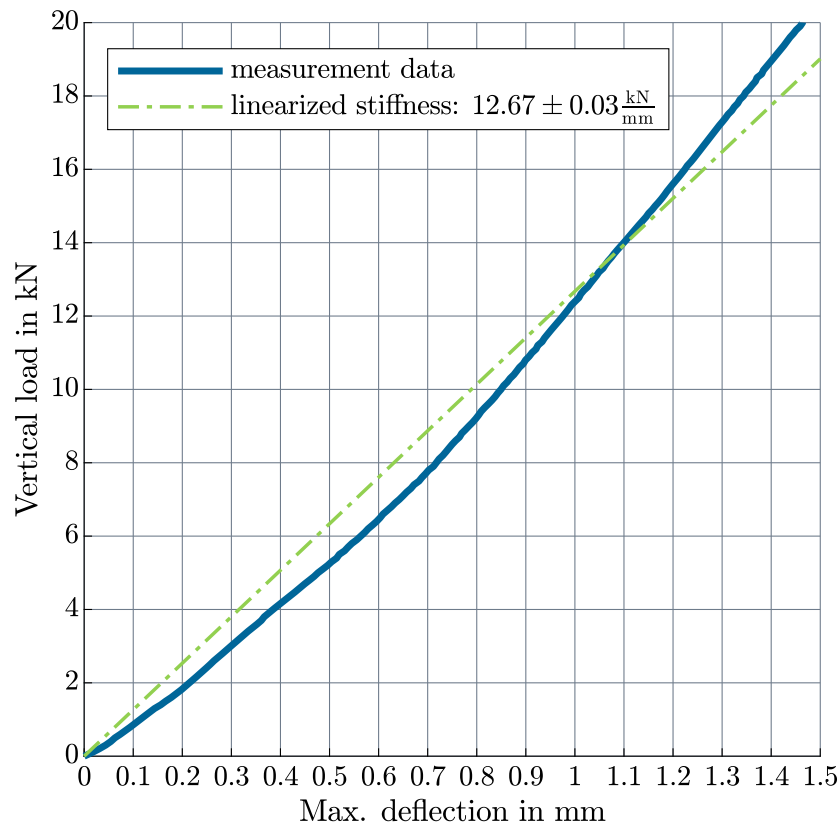

Fig. 5 Vertical load vs. deflection at force application point (experimental data)

\section{Sources of nonlinear behavior}

Figure 5 plots the applied concentrated force over the deflection of the force application point. The blue line represents the mean of the measuremend data for five repetitions, and the green line represents the linearized data with its range of deviations between the load level of $0 \mathrm{kN}$ and $20 \mathrm{kN}$. The occurring forming forces during production can reach higher load levels. In order to avoid surface damage on the lower shaft (small contact area), the upper limit is set to $20 \mathrm{kN}$. When the two lines are compared, a progressive stiffness behavior can easily be observed. This means that by increasing the load level, the overall stiffness increases. The following sections further discuss the causes of nonlinearity. The nonlinear behavior may originate from the bearings and the changing contact conditions between the guide posts and the bearing pedestals on the drive-side.

\subsection{Continuum FEM model in ANSYS}

A continuum FEM model with the commercial software ANSYS is set up, in order to gain a deeper understanding of the observed nonlinear effects. As just the deflections of the lower shaft are of interest in this study, only the lower shaft with its pedestals and guide posts is considered in the model. The forming stands are omitted, which allows a direct comparison with the compensated measurement data. As the material is isotropic and the whole experimental setup is symmetric about the XY-plane, only half of the model is discretized with quadratic hexahedron elements. 
The displacement boundary conditions of the bearing pedestals in $y$-direction are set to zero at the location of the spindle axis, which allows tilting of the pedestals but no vertical movement. The guide posts are cut at the height of the upper surface of the mill bed mountings and all degrees of freedom are locked there. The only contact area in den model is defined between the guide posts and the pedestals. In order to determine the nonlinear load/moment over displacement/rotation (with operating clearances) behavior, connectors are used. As the rolling elements of the bearings can only transmit compression stresses, only the corresponding upper or lower area of the projection of the bearings on the pedestals and shaft are coupled (ball bearing not pretensioned). The external maximum force for the FEM calculation is extended to $35 \mathrm{kN}$ in order to investigate the behavior of the shaft under higher loads.

\subsection{Radial and tilting stiffness of the bearings}

In needle roller bearings, there is, theoretically, a line contact between the rolling elements and the inner and outer rings. In ball bearings, on the other hand, there is, in theory, a point contact between the rolling elements and the inner and outer rings. The result is a much higher radial stiffness of the needle roller bearings. The radial load over displacement that is characteristic of both bearing types can be described with a power function, and both bearing types display a progressive behavior.

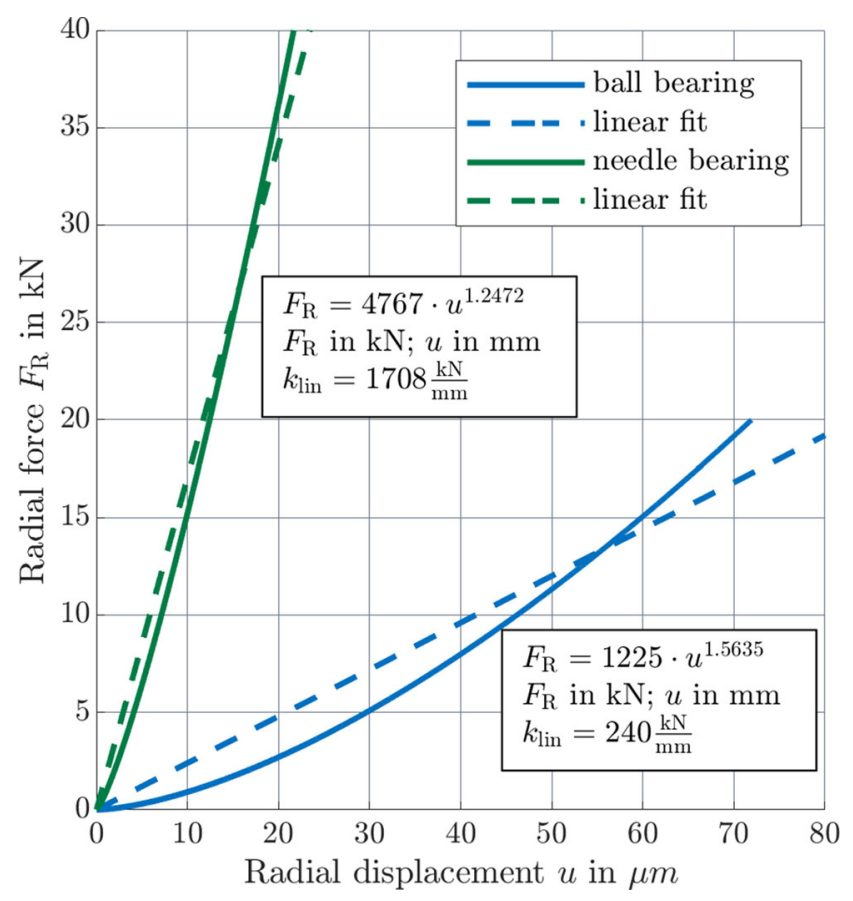

Fig. 6 Radial stiffness of the needle roller bearing and angular contact ball bearing (data from manufacturer)
Higher load leads to higher deformation of the rolling elements and the rings and, therefore, to a lager contact area. The pressure distribution in the contact zones can be described by means of the Hertzian theory. Figure 6 shows the force over displacement curves of the two bearing types (experimental data from manufacturer). To obtain these curves, only a radial force is applied on the inner ring of the bearing. The linearized values are calculated between $0 \mathrm{kN}$ and $20 \mathrm{kN}$ for the angular contact ball bearing and between $0 \mathrm{kN}$ and $40 \mathrm{kN}$ for the needle roller bearing. The different force ranges for the linearization are due to the different support reactions. Compared with the angular contact ball bearing, the needle roller bearing is about seven times stiffer. If the radial bearing stiffnesses (see Fig. 6) are divided by the linearized stiffness of the whole system (measurement data: vertical load vs. deflection at the force application point; see Fig. 5), we get a factor of about 135 for the needle roller bearing and a factor of about 19 for the angular contact ball bearing. As the linearized bearing stiffnesses are way higher compared to the linearized overall stiffness, it is to say that the main source of nonlinear behavior of the system cannot be explained by just the nonlinear radial stiffness. In fact, one could deduce that it does not make a difference whether the linearized radial stiffness or the actual nonlinear behavior of the bearing is used in the nonlinear model.

In addition to the radial stiffness, the needle roller bearing has a tilting stiffness. Because the angular contact ball bearing is not pretensioned, the tilting stiffness can be assumed to be zero. The tilting stiffness of the needle
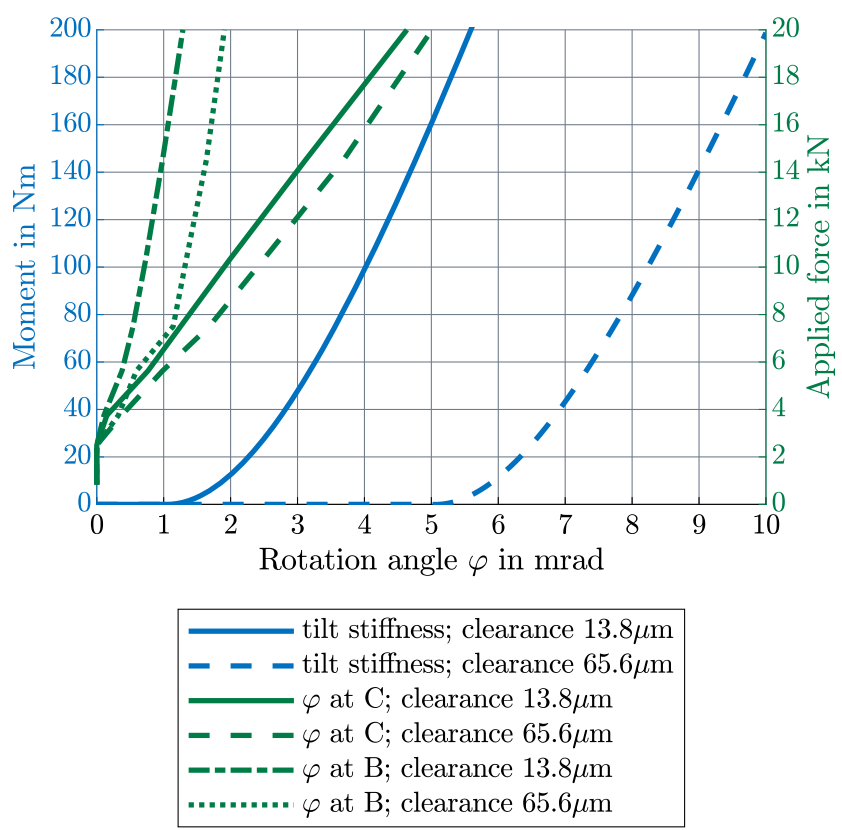

Fig. 7 Tilting stiffness of the needle roller bearings and their actual rotation angle (data from manufacturer and results of 3D FEM model) 
Fig. 8 Ideal pinned-roller-roller support model of the shaft

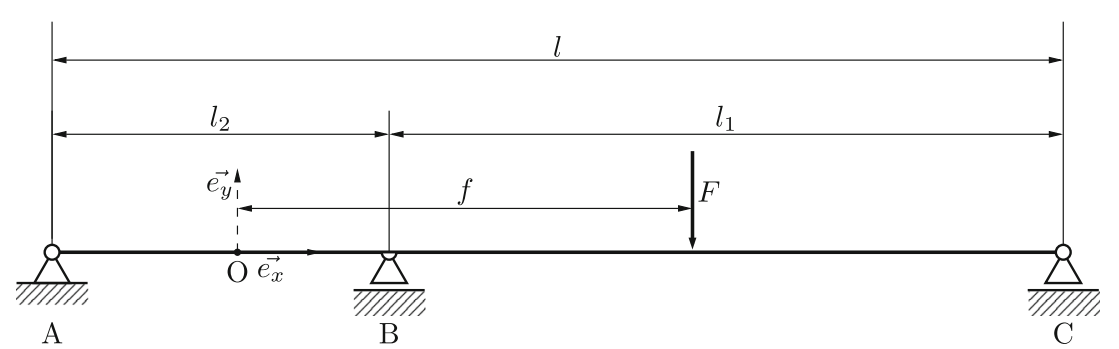

roller bearings is shown in Fig. 7 (blue lines-experimental data from manufacturer). Due to the possible operating clearance of the bearings, the tilting stiffness is expected to be of no impact. To establish which clearance actually predominates in the presented case, the two extreme cases (maximum and minimum clearances) are computed. The calculated deflections with the maximum clearance show the best correspondence with the experimental data, so the assumption can be made that the clearance of the needle roller bearing is around $65.6 \mu \mathrm{m}$. Figure 7 also displays the rotation angle over the applied force for points B and C (green lines in Fig. 8). If the operating clearance is $65.6 \mu \mathrm{m}$, no moment owing to the tilting stiffness of the needle roller bearing is induced in the shaft. At point $\mathrm{B}$, the rotation angle is much smaller than at point $C$. The support at point $C$ can be seen as an ideal hinge. Neither the radial bearing stiffness nor the tilting stiffness of the bearings has a major influence on the nonlinear behavior of the system.

\subsection{Development of the support reactions over the induced load}

As shown in Fig. 8, the angular contact ball bearing at point $\mathrm{A}$ acts as a fixed bearing, and the needle roller bearings at points $\mathrm{B}$ and $\mathrm{C}$ act as floating bearings. Accordingly, it is a statically over-determined system.

The operating clearance is $65.6 \mu \mathrm{m}$ for the needle roller bearing and $27 \mu \mathrm{m}$ for the angular contact ball bearing. In a statically overdetermined system, the support reactions are dependent on the bending stiffness of the beam. In addition, the clearance of the needle roller bearing and the angular contact ball bearing on the drive-side are responsible for a change of the force direction at point A.

Figure 9 displays the reaction forces at the supports (results of 3D FEM model) over the external force. The green line represents the reaction force at the operatorsided needle roller bearing, and the blue line represents the drive-side forces. Up to an external force of $4 \mathrm{kN}$, all forces are in the positive $y$-direction. The clearance of the angular contact ball bearing is smaller than that of the needle roller bearing, which means that the angular contact ball bearing gets in contact first. Therefore, the pedestal tilts counterclockwise, which leads to an immediate contact of the needle roller bearing. If the external load further increases, the pedestal tilts clockwise and the force magnitude of the contact ball bearing starts to decrease at a force level of $4 \mathrm{kN}$. At a force level of $6 \mathrm{kN}$, the angular contact ball bearing is no longer in contact; thus, the reaction force tends to $0 \mathrm{kN}$. By continuing to increase the external load level, the reaction force becomes negative, so that the angular contact ball comes into contact with the upper part of the pedestal. During this low external load level, the overall stiffness of the system starts to increase. Starting at a force level of $6 \mathrm{kN}$, the angular contact ball bearing creates an opposing force, thereby stiffening the system. From a force level of around $16 \mathrm{kN}$, all reaction forces increase linearly. Hence, the overall stiffness also becomes linear. This can also be observed by looking at the results of the finite element calculation of the 3D model. To sum up, the operation clearance of the bearings is a major source of nonlinearity.

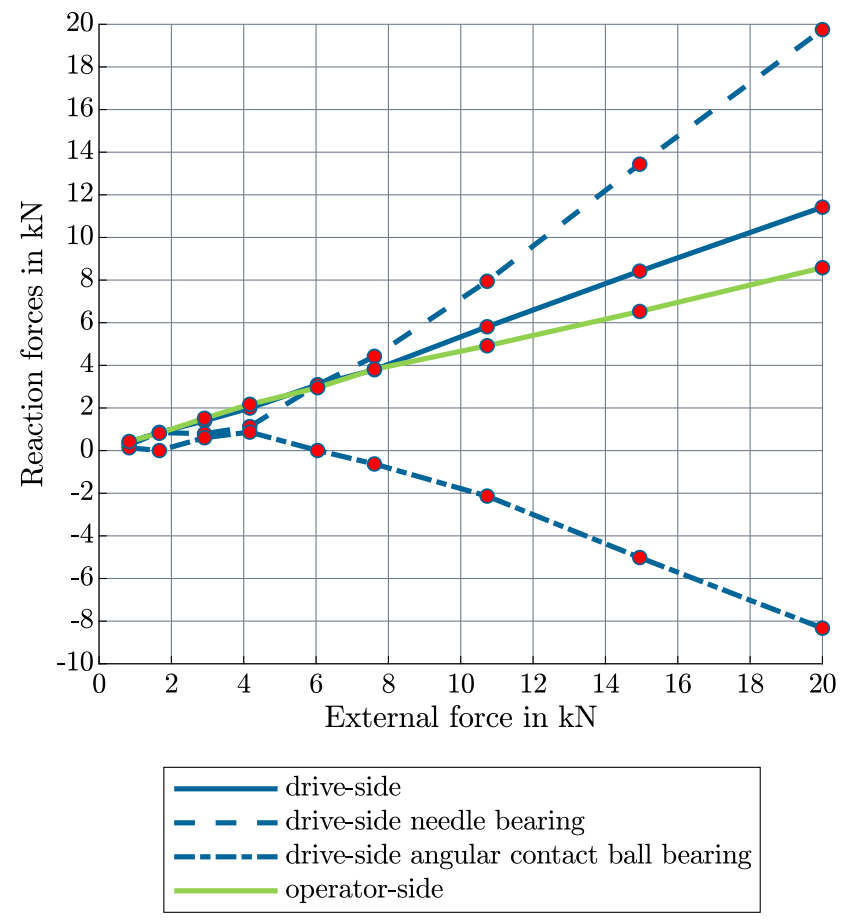

Fig. 9 Reaction forces at the three supports (data from 3D FEM model) 


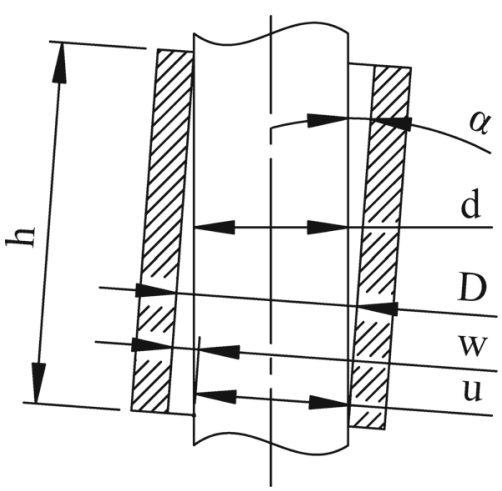

Fig. 10 Tilting of pedestals due to clearance

\subsection{Tilting of bearing pedestals}

Due to the clearance between the bearing pedestals and the guide posts, which is assumed with $0.2 \mathrm{~mm}$, the bearing pedestals can tilt. This leads to an increased deflection of the shaft. Figure 10 shows the geometric relations.

The angle of inclination $\alpha$ of the pedestals can be calculated thus:

$$
\begin{aligned}
\cot (\alpha) & =\frac{h}{w}, \cos (\alpha)=\frac{d}{u}, u+w=D \\
\cos (\alpha) D & =\sin (\alpha) h+d \rightarrow \alpha \approx \frac{D-d}{h}
\end{aligned}
$$

The free rotation angle $\alpha_{0}$ of the drive-side bearing pedestal is, due to clearance, up to $1.48 \mathrm{mrad}$. Because of the induced moment, the contact area between the guide posts and the pedestals is dependent on the external force. The moment leads to a deflection of the guide posts.

\section{Mechanical models and implementation}

In this section, the development of a suitable beam model, which has to show high accuracy compared to the measurement data, is presented. This can be seen as an general approach starting with the simplest beam models to finally end up with a beam model with nonlinear elastic springs. For all upcoming models, the shaft is considered as a fully linear, shear deformable beam (Timoshenko theory). It is exposed to a single force $F$ that is acting in the vertical direction (negative $y$-direction).

\subsection{Simple linear models}

As a first attempt to describe the deflection of the shaft, the ideal pinned-roller-roller support model in Fig. 8 is used. For this model, all supports are fixed in the vertical
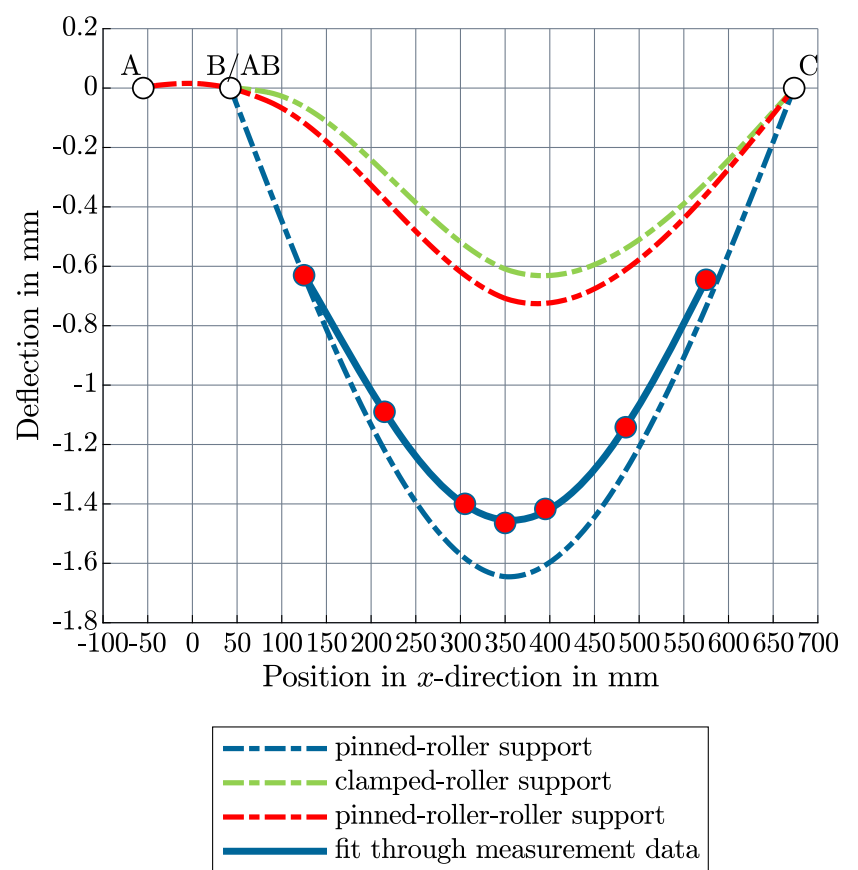

Fig. 11 Comparison between simple models and results of the experiments for external load of $20 \mathrm{kN}$

direction. The origin of the coordinate system in the $x$ direction is on the axis of the guide posts on the drive-side.

The red line in Fig. 11 shows the computed bend-line for the ideal pinned-roller-roller support model (Fig. 8) for a concentrated force of $20 \mathrm{kN}$. The red dots represent the discrete displacement values of the LVDT sensors, where the deflections of the bearing pedestals are already compensated. The blue line is the polynomial fit through the measurement data. If the measured deflection data are compared with the ones of the ideal pinned-roller-roller support model, it becomes obvious that the model highly overestimates the stiffness of the shaft. This means that the stiffness of the drive-side is not as high as in the ideal case, because the supports A and B move in vertical direction due to the phenomenons described in Sections 3.2, 3.3 and 3.4. So the basic assumptions that are normally made for ideal supports are not valid in this case. In what follows, the two extreme cases concerning the stiffening effect of the drive-side pedestal are presented in order to estimate the boundaries of the possible deflections.

The bend-lines for the two models are also shown in Fig. 11. For the ideal clamped-roller support model (Fig. 12) and the ideal pinned-roller support model (Fig. 13), the supports A and B of the ideal pinned-roller-roller support model (Fig. 8) of the shaft are reduced to one support AB, which is at the horizontal position of $\mathrm{B}$ from the ideal pinned-roller-roller support model. The minimal deflections would occur if the drive-side is modeled as a clamped 


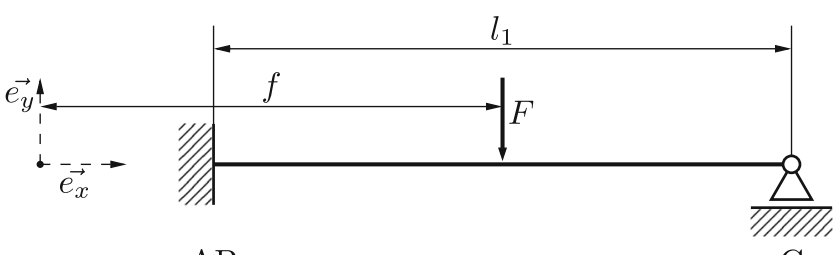

$\mathrm{AB}$

Fig. 12 Ideal clamped-roller support model

support (Fig. 12). The maximal deflections, on the contrary, would occur if the drive-side is represented by a simple pinned support (Fig. 13). The ideal pinned-roller-roller support model (Fig. 8) is nearly as stiff as the clampedroller support model (Fig. 12). However, both overestimate the stiffness of the experimental bending-line. The pinnedroller support model (Fig. 13), on the other hand, is too compliant, but it is still the model that best describes the bend-line. So the stiffening effect of the drive-side angular contact ball bearing is not as high as assumed. For all models, the Timoshenko beam theory is used; the differential equations for the bend-line are:

$$
\begin{aligned}
\frac{\mathrm{d} w(x)}{\mathrm{d} x} & =-\varphi(x)+\frac{Q(x)}{G A k_{\mathrm{s}}} \\
\frac{\mathrm{d} \varphi(x)}{\mathrm{d} x} & =\frac{M(x)}{E J_{\mathrm{Z}}}
\end{aligned}
$$

Here $E$ is the Young's modulus, $J_{\mathrm{Z}}$ is the second moment of area about the neutral axis $z, M$ is the moment about the neutral axis, $G$ is the shear modulus, $w$ is the deflection in the negative $y$-direction, $A$ is the area of the cross section, $k_{\mathrm{S}}$ is the shear correction factor, and $\varphi$ is the angle of inclination of the cross section. As the shaft is stepped, the diameter and therefore $A$ and $J_{\mathrm{Z}}$ are dependant on the position in $x$-direction. The kinematic assumptions of the Timoshenko theory are that the normals to the axis of the beam remain straight after deformation and that the thickness of a cross-section does not change during the deformation. In contrast to what the Bernoulli-Euler theory says, the angle $\varphi$ is not simply the derivative of the deflection. The angle between the normal to the crosssection and the vertical axis is greater than $90^{\circ}$ because of the additional shear deformation. As a consequence, a Bernoulli-Euler beam is stiffer and experiences lower deflections than a Timoshenko beam. In the particular case of the considered shaft, the maximum relative error of deflection between Bernoulli theory and Timoshenko theory for the three models at a force level of $20 \mathrm{kN}$ is $5.7 \%$.

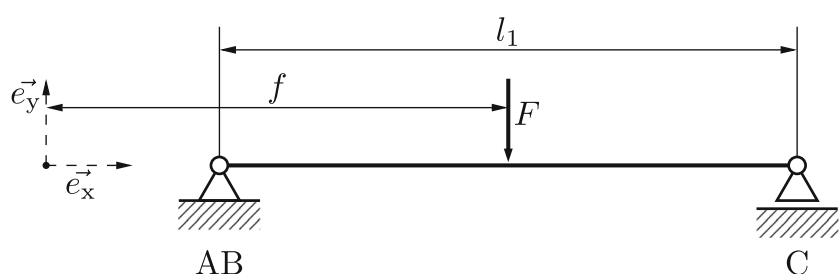

Fig. 13 Ideal pinned-roller support model

Thus, only the Timoshenko theory is relevant to the study presented here. The diagram also shows that the bend-line is not symmetrical between $\mathrm{B}$ and $\mathrm{C}$.

\subsection{Linear and nonlinear models with springs}

The final model to describe the stiffness behavior is an adaption of the simple pinned-roller support model (see Fig. 13). The supports are modeled by two linear vertical acting springs and one rotational spring (see Fig. 14). The two linear springs represent the linearized radial stiffness of the needle roller bearings with linear stiffness values of $k_{\mathrm{ABT}}=k_{\mathrm{CT}}=1708 \cdot 10^{3} \frac{\mathrm{N}}{\mathrm{mm}}$ (see Fig. 6). These values are kept constant, as the system does not react sensitively to their variation.

Preliminary experiments with a rotational spring at point $\mathrm{C}$ have demonstrated that this position (operatorside) has no notable tilting stiffness and is far less stiff than the drive-side. Thus, a rotational spring in position $\mathrm{C}$ is omitted. A rotational spring at point $\mathrm{AB}$ accounts for the stiffening effect of the drive-side. The reduced center of rotation of the needle roller bearing, the angular contact ball bearing on the drive-side as well as the bearing pedestal has to be between the two bearings. Therefore, the position of point $\mathrm{AB}$, which is equivalent to the effective length $l_{M}$ between the supports, will be determined in the course of the identification of the parameters. For the rotational spring, a linear as well as a nonlinear approach is chosen. The rotational moments and the potential energies of the spring are thus determined by the following expressions:

$$
\begin{aligned}
\text { Linear : } & M_{\mathrm{AB}}(\varphi)=k_{\mathrm{AB}} \varphi \\
\text { Nonlinear : } & M_{\mathrm{AB}}(\varphi)=k_{1 \mathrm{AB}} \varphi+k_{2 \mathrm{AB}} \varphi^{3} \\
\text { Linear : } U_{\mathrm{AB}}(\bar{\varphi}) & =\int_{0}^{\bar{\varphi}} M_{\mathrm{AB}}(\varphi) \mathrm{d} \varphi=\frac{1}{2} k_{\mathrm{AB}} \bar{\varphi}^{2} \\
\text { Nonlinear : } U_{\mathrm{AB}}(\bar{\varphi}) & =\frac{1}{2} k_{1 \mathrm{AB}} \bar{\varphi}^{2}+\frac{1}{4} k_{2 \mathrm{AB}} \bar{\varphi}^{4}
\end{aligned}
$$




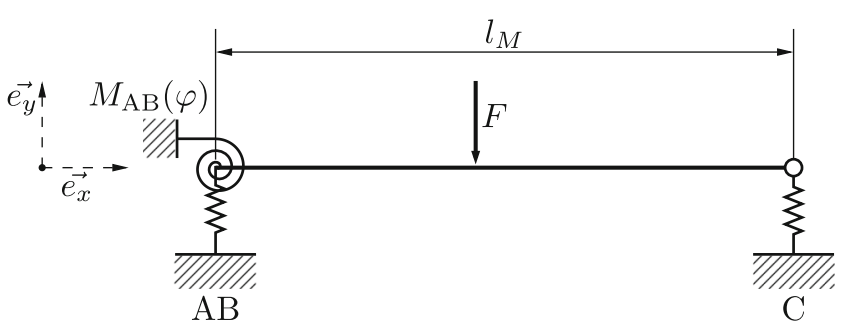

Fig. 14 Linear and nonlinear model with springs

Here we omit the quadratic term of the nonlinear spring based on the assumption that the supports react symmetrically to the load (e.g., $F$ and $-F$ should cause reactions of the same magnitude). In Section 4.4, the values of the two parameters $l_{M}$ and $k_{\mathrm{AB}}$ for the linear model and the three parameters $l_{M}, k_{1 \mathrm{AB}}$, and $k_{2 \mathrm{AB}}$ for the nonlinear model will be determined in the course of the identification of the parameter.

\subsection{Implementation of the FE model}

We discretize the beam with shear deformable 1D-beam elements, as shown in Fig. 15. The element is of the length $l_{e}$ and possesses three nodes, namely $i, j$, and $k$. The local element coordinates $-1 \leq \xi \leq 1$ have their origin in the center of the element. Each node receives a degree of freedom (DOF) for deflection, denoted as $w$, but only the outer two nodes $i$ and $k$ are assigned a rotational DOF $\varphi$. The local element-coordinate vectors can then be introduced as follows:

$\mathbf{u}_{\mathbf{e l}}=\left(w_{\mathrm{i}} w_{\mathrm{j}} w_{\mathrm{k}}\right)^{\mathrm{T}}, \quad \boldsymbol{\varphi}_{\mathrm{el}}=\left(\varphi_{\mathrm{i}} \varphi_{\mathrm{k}}\right)^{\mathrm{T}}$

$\mathbf{u}_{\mathrm{el}}$ contains the DOFs for deflection, and $\varphi_{\mathrm{el}}$ those for the rotational angles. As for the kinematics of the element, we use a quadratic ansatz for the deflection and a linear ansatz for the rotation angle:

$$
\begin{aligned}
& w_{\mathrm{el}}(\xi)=\frac{1}{2}\left(w_{\mathrm{i}}(-1+\xi) \xi+w_{\mathrm{k}}(1+\xi) \xi-2 w_{\mathrm{j}}\left(-1+\xi^{2}\right)\right) \\
& \varphi_{\mathrm{el}}(\xi)=\frac{1}{2}\left(\varphi_{\mathrm{i}}(1-\xi)+\varphi_{\mathrm{k}}(1+\xi)\right)
\end{aligned}
$$

The considered problem (see Fig. 14) is both a conservative and a static problem. Thus, the chosen

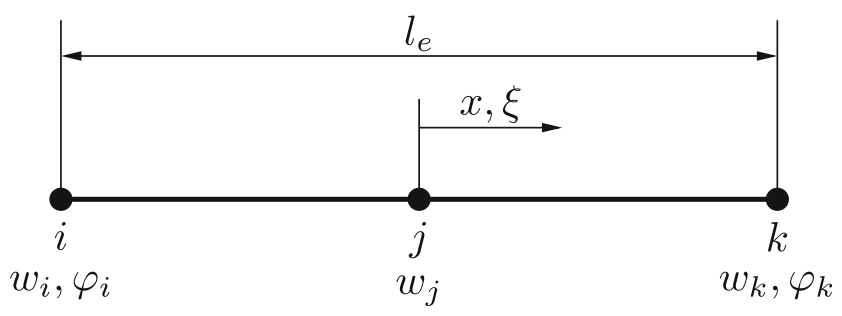

Fig. 15 Shear deformable beam element approach is to minimize the total potential energy of the system. The total energy $U_{\text {total }}$ is the sum of the strain energy of the beam elements $U_{\text {int }}$, the deformation energy of the springs $U_{\text {springs }}$, and the energy of the external forces $U_{\text {ext }}$ :

$U_{\text {total }}=U_{\text {strain }}+U_{\text {springs }}+U_{\text {ext }}$.

The strain energy of a single shear deformable beam element $n$ as $U_{\mathrm{el}}^{(n)}$ is defined as:

$$
\begin{aligned}
U_{\mathrm{el}}^{(n)}=\frac{l_{\mathrm{e}}}{4} \int_{\mathrm{el}^{(n)}} & \left(E J_{\mathrm{Z}}\left(\frac{\mathrm{d} w_{\mathrm{el}}(\xi)}{\mathrm{d} \xi}\right)^{2}\right. \\
& \left.+\kappa_{\mathrm{S}} G A\left(\frac{\mathrm{d} w_{\mathrm{el}}(\xi)}{\mathrm{d} \xi}-\varphi_{\mathrm{el}}(\xi)\right)^{2}\right) \mathrm{d} \xi .
\end{aligned}
$$

In Eq. 7, $A$ stands for the cross-sectional area, and $J_{\mathrm{Z}}$ denotes the area moment of interia around the $z$-axis. Both are functions of $\xi$. The other properties have been defined above. After introducing an appropriate mapping scheme of the local element DOFs to the entries of the vector of the global DOFs $\boldsymbol{q}$, the sum over the internal energies of each beam element results into the total strain energy $U_{\text {strain }}\left(q_{k}\right)$. The integrals are computed using the Gauss quadrature rule with two integration points per element. This process of assembling the expression for the total strain energy can be schematically represented as follows:

$$
\begin{aligned}
\left\{w_{\mathrm{i}}^{(n)}\right. & \rightarrow \boldsymbol{q}\left[3 \mathrm{el}^{(n)}-2\right], \varphi_{\mathrm{i}}^{(n)} \rightarrow \boldsymbol{q}\left[3 \mathrm{el}^{(n)}-1\right], \\
w_{\mathrm{j}}^{(n)} & \rightarrow \boldsymbol{q}\left[3 \mathrm{el}^{(n)}\right], w_{\mathrm{k}}^{(n)} \rightarrow \boldsymbol{q}\left[3 \mathrm{el}^{(n)}+1\right], \\
\varphi_{\mathrm{k}}^{(n)} & \left.\rightarrow \boldsymbol{q}\left[3 \mathrm{el}^{(n)}+2\right]\right\} \\
U_{\mathrm{strain}} & =\sum_{n=1}^{N_{\mathrm{el}}} U_{\mathrm{el}}^{(n)},
\end{aligned}
$$

was implemented using the Wolfram Mathematica computer algebra environment ${ }^{1}$.

In Eq. 8, $N_{\mathrm{el}}$ denotes the total number of elements used for discretization.

Subsequently, the deformation energy of the springs is defined in Eq. 9. One can identify the global DOFs that are associated with the springs in a straightforward way,

\footnotetext{
${ }^{1}$ http://www.wolfram.com/mathematica
} 
since the springs act on the first and the last element of the established mesh (mapping scheme according to Eq. 8).

$$
\begin{aligned}
\text { Linear : } U_{\text {springs }}= & \frac{1}{2} k_{\mathrm{ABT}} \boldsymbol{q}[1]^{2}+\frac{1}{2} k_{\mathrm{CT}} \boldsymbol{q}\left[3 N_{\mathrm{el}}+1\right]^{2} \\
& +\frac{1}{2} k_{\mathrm{AB}} \boldsymbol{q}[2]^{2} \\
\text { Nonlinear : } U_{\text {springs }}= & \frac{1}{2} k_{\mathrm{ABT}} \boldsymbol{q}[1]^{2}+\frac{1}{2} k_{\mathrm{CT}} \boldsymbol{q}\left[3 N_{\mathrm{el}}+1\right]^{2} \\
& +\frac{1}{2} k_{1 \mathrm{AB}} \boldsymbol{q}[2]^{2}+\frac{1}{4} k_{2 \mathrm{AB}} \boldsymbol{q}[2]^{4}
\end{aligned}
$$

As for the energy of the external forces, only a single force $F$ is acting on the system, and the energy results in:

$$
U_{\mathrm{ext}}=\left.F w_{\mathrm{el}}(\xi)\right|_{\xi=\xi_{\mathrm{F}}}
$$

In Eq. 10, it is necessary to convert the local DOFs into the appropriate global DOFs (according to Eq. 8). Therefore, the element on which $F$ is acting and the local position of $F$ on this element, which is denoted by $\xi_{F}$, must be known.

A solution (equilibrium state) of the generalized nodal displacements is obtained by minimizing $U_{\text {total }}$. To enable this condition, the gradient of $U_{\text {total }}$ must be equal to zero. Thus, we obtain a system of nonlinear algebraic equations

$$
\frac{\partial U_{\mathrm{total}}}{\partial q_{i}}=0, \text { for } i=\left\{1,2,3, \ldots, 3 N_{\mathrm{el}}+2\right\}
$$

which is solved iteratively with the help of Newton's method using the Wolfram Mathematica software environment.

\subsection{Objective function for optimization}

In order to adapt the existing numerical models in accordance with the experiments conducted, a parameter identification or optimization must be carried out. The aim is to identify the length $l_{M}$ and the spring parameters $k_{\mathrm{AB}}$ for the linear model as well as $k_{1 \mathrm{AB}}$ and $k_{2 \mathrm{AB}}$ for the the nonlinear model such that the results of the numerical simulation are as close as possible to the measured deflections along the beam and for the entire range. The identification is conducted for a set of different loads:

$$
\boldsymbol{F}=\{20 \mathrm{kN}, 15 \mathrm{kN}, 10 \mathrm{kN}, 3 \mathrm{kN}, 1 \mathrm{kN}\}
$$

The objective functions, which are desired to be minimized, are introduced as follows:

$$
\begin{gathered}
R_{j}=\left.\left(\frac{\sum_{i=1}^{i=7}\left(w_{i}-M_{i}\right)^{2}}{\sum_{i=1}^{i=7} M_{i}^{2}}\right)\right|_{F=F[j]} \\
\text { Linear: } \operatorname{Obj}\left(l_{M}, k_{\mathrm{AB}}\right)=\sum_{j=1}^{j=5} R_{j} \\
\text { Nonlinear: } \operatorname{Obj}\left(l_{M}, k_{1 \mathrm{AB}}, k_{2 \mathrm{AB}}\right)=\sum_{j=1}^{j=5} R_{j}
\end{gathered}
$$

Here $w_{i}$ are the numerically predicted deflection value for the discrete displacement sensor position $i$ at the load level $j$ and $M_{i}$ are corresponding measured values. The objective function used is the sum over the relative errors $R_{j}$. They are defined for a certain load $F=$ $\boldsymbol{F}[j]$, as the computed error sum of squares $\sum\left(w_{i}-M_{i}\right)^{2}$ divided by the sum of squares of the measurement values $\sum M_{i}^{2}$ such that all measurements become equally important.

As already mentioned, the upper bound is set to $20 \mathrm{kN}$ in order to avoid surface damage. In contrary, the lower bound of $1 \mathrm{kN}$ is set due to the fact that lower load levels for this type of roll forming machine are not applicable. The problem at hand is also bound up with constraints, as the stiffness parameters of the springs must be positive and the length in the range of $631 \mathrm{~mm}<$ $l_{M}<728 \mathrm{~mm}$ (position between the needle and the ball bearing).

Upon minimizing the objective function, the according parameters can be found. To minimize the objective function, the Newton method is applied.

\section{Results}

\subsection{Parameter identification results of the linear model with springs}

The identified parameters for the linear model are depicted in Table 2 and the corresponding bend-lines for the different loads as dashed lines are displayed in Fig. 16. The solid lines, which are the polynomial fit through the discrete measured deflections, serve as a reference for the accuracy of the used model.

As for the optimization of the linear rotational spring, all loads are considered, and it is to be expected that a 
Table 2 Identified parameters $l_{M}$ and and $k_{\mathrm{AB}}$

$l_{M}=679 \mathrm{~mm} \quad k_{\mathrm{AB}}=1.3 \cdot 10^{8} \frac{\mathrm{Nmm}}{\mathrm{rad}}$

deflection curve in the medium load range best complies with the experimental data, which is the case for a load of $10 \mathrm{kN}$. For other loads, however, there is a larger deviation between the experimental data and the predicted deflections, which again emphasizes the nonlinearity present in the system. On the one hand, for the lower loads, the model is too stiff on the other hand for higher load levels too compliant. Thus, a nonlinearity can be observed and good compliance as to the measurements and the fully linear model is, in general, not achievable for a load that can take on values in a large range. The point $\mathrm{AB}$ shifts $48 \mathrm{~mm}$ in negative $x$-direction compared to point $\mathrm{B}$ in the ideal pinned-roller support model (compare to Fig. 8).

The solutions for the linear model were verified by comparing them with the results of the analytical solution of the equations of the beam theory. This comparison also makes it possible to test the convergence of the finite element model. The relative error of deflection of the analytical solution in comparison with the numerical solution, at the position where $F$ is acting, is plotted against the number of elements (see Fig. 17). Since the slope of the linear function (due to logarithmic scaling) is about 2, a quadratic convergence is observed.

The convergence test was only carried out for the linear model. We defined a relative error of around $10^{-3}$ as

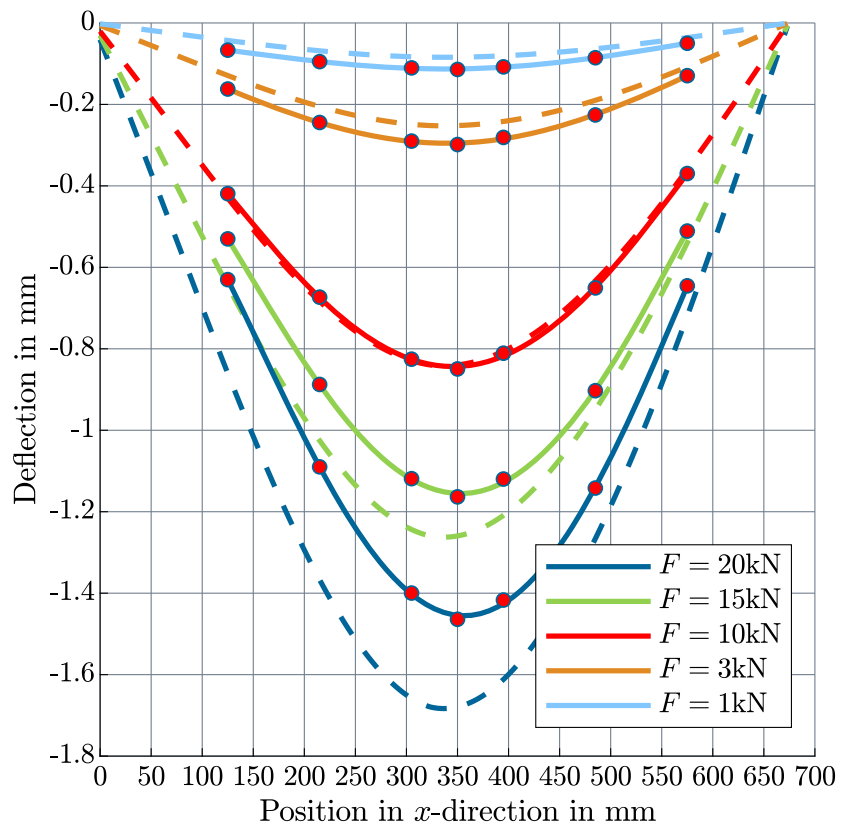

Fig. 16 Deflection curves of linear model

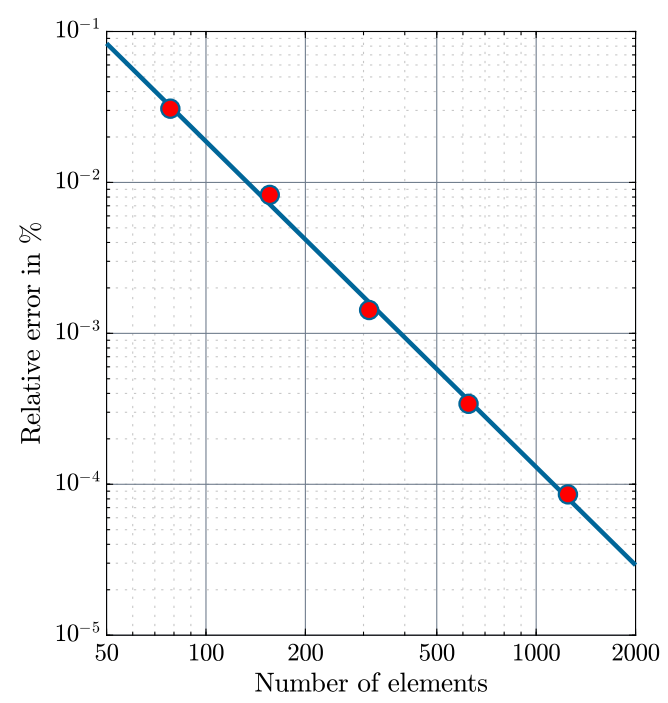

Fig. 17 Convergence analysis

acceptable. Therefore, for subsequent computations, a mesh density of around $0.5 \frac{\text { elements }}{\mathrm{mm}}$ is defined. This corresponds to a discretization with a total number of 340 elements.

\subsection{Parameter identification results of the nonlinear model with springs}

The coefficient of the linear term in the rotational spring characteristic results to zero (see Table 3). Thus, only the cubic term in the characteristic remains.

Since the value of $k_{2 \mathrm{AB}}$ is high, the rotational spring displays a rather stiff behavior. Interestingly, the bearing characteristic in Fig. 6 shows a qualitatively similar cubic behavior. Regarding the results of the nonlinear model (Fig. 18), a great improvement can be deduced, since the compliance of the measurements with the predicted deformations is quite good, even over the whole range of loads. The optimal length $l_{M}$ has the same value as for the linear model. To further quantify the occurring deviations in the linear model compared to the ones of the nonlinear model and to emphasize the superior compliance in the nonlinear model, Fig. 19 plots the relative errors. The relative errors are defined according to Eq. 12.

The maximum relative error for the linear model is around $8 \%$ in the linear model, whereas in the nonlinear model, it is less than $0.05 \%$, except for the load of $1 \mathrm{kN}$, it is around $2 \%$. For a load of $10 \mathrm{kN}$, the linear model even has a smaller error than the nonlinear model.

Table 3 Identified parameters $l_{M}, k_{1 \mathrm{AB}}$, and $k_{2 \mathrm{AB}}$

$l_{M}=679 \mathrm{~mm} \quad k_{1 \mathrm{AB}}=0 \frac{\mathrm{Nmm}}{\mathrm{rad}} \quad k_{2 \mathrm{AB}}=1.39 \cdot 10^{13} \frac{\mathrm{Nmm}}{\mathrm{rad}}$




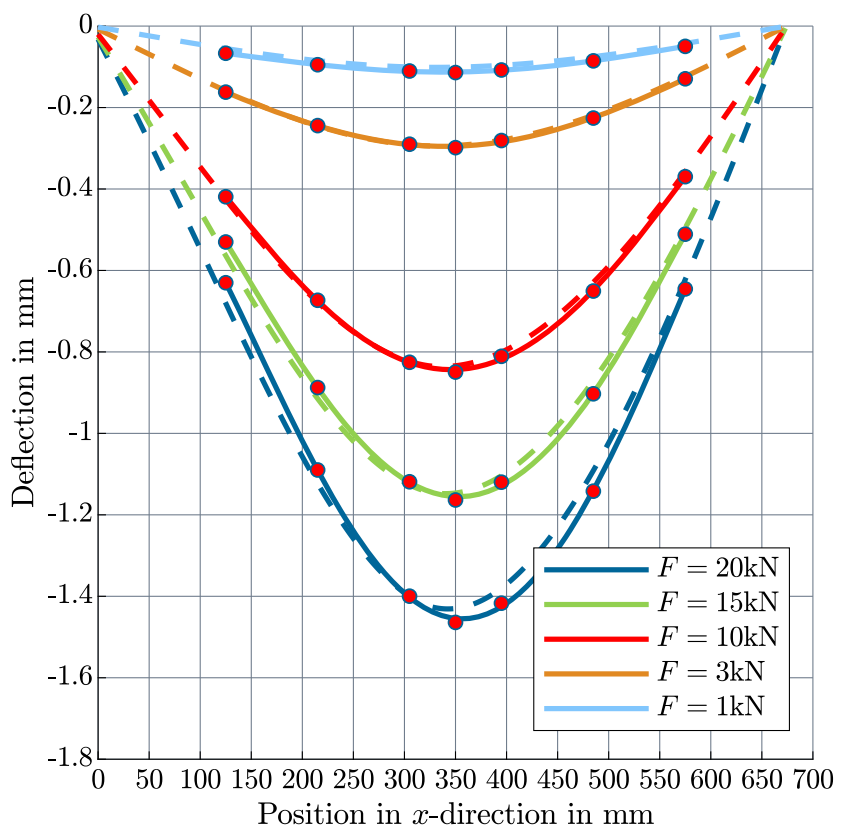

Fig. 18 Deflection curves of nonlinear model

\subsection{Additional results of the nonlinear model}

Furthermore (in Fig. 20), the adjusting rotation angles in the supports are plotted over the same discrete load range as before. As is to be expected, the green curve, denoting the drive-side rotation angles, shows a larger slope than the blue curve, denoting the rotation angles on the operation-side. Thus, the drive-side indeed acts more stiffly

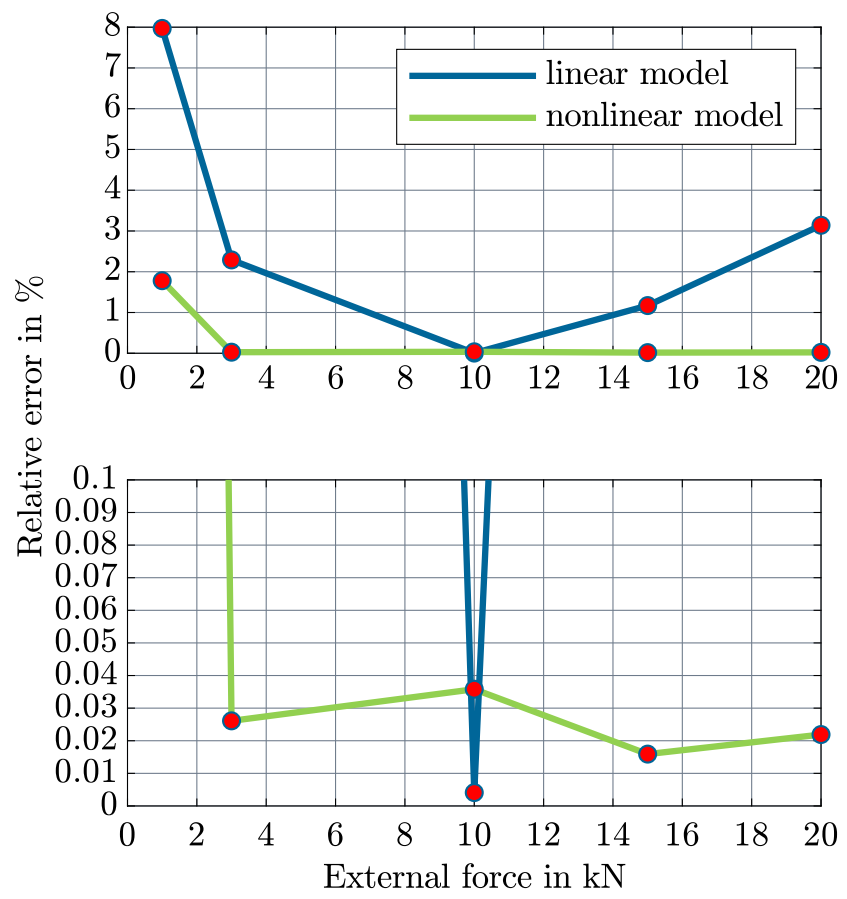

Fig. 19 Relative errors: linear model vs. nonlinear model

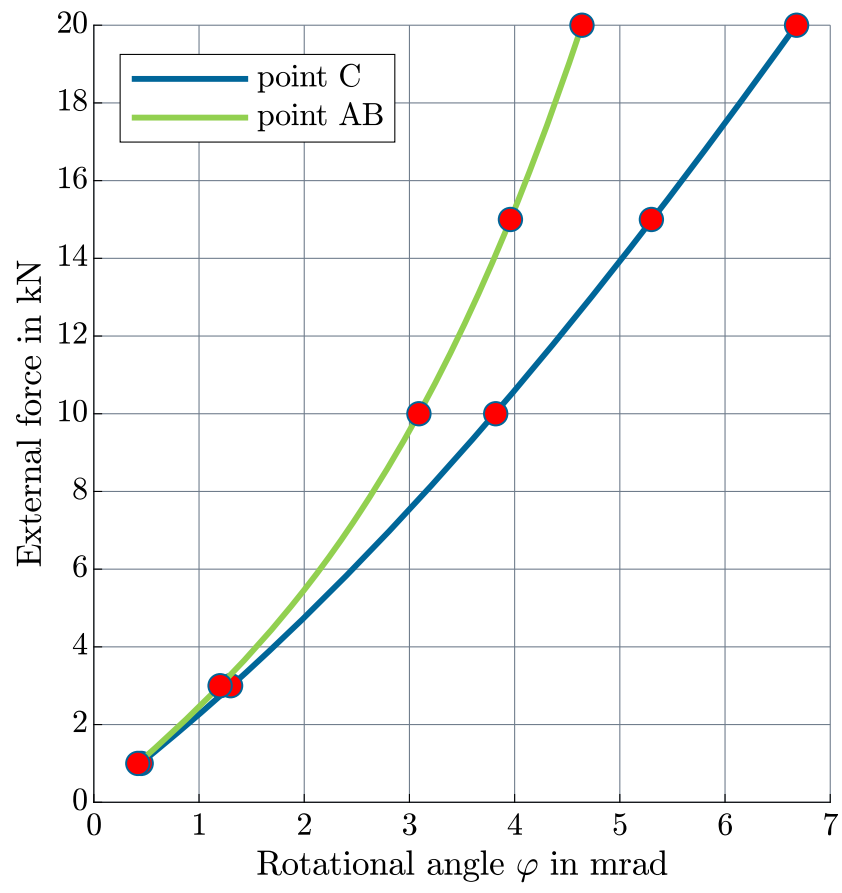

Fig. 20 Resulting rotational angle $\varphi$ in the supports $\mathrm{AB}$ and $\mathrm{C}$

than the operation-side. The curves for interpolating the discrete points in Fig. 20 are cubic functions, which seem appropriate for description.

Finally, in Fig. 21, we plot the identified nonlinear bending moment characteristic of the support of the operator-side. This moment corresponds to the used cubic

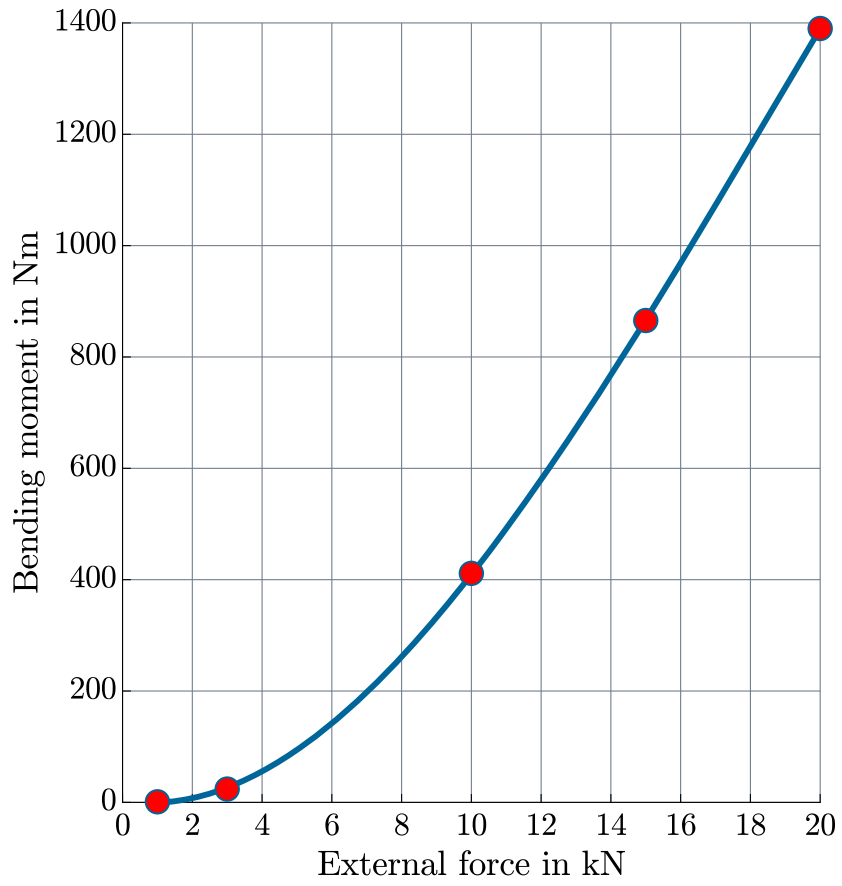

Fig. 21 Bending moment $M_{\mathrm{AB}}$ at point $\mathrm{AB}$, against the external force $F$ 
spring characteristic of Eq. 3. However, in Fig. 21, the moment is plotted over the load, instead of the rotation angle of the drive-side.

\section{Conclusion}

The nonlinear stiffness behavior of the shaft without equipped rolls of a rolling stand of a conventional mill was investigated in the study presented here. The objective was to find out which parameters influence the nonlinear behavior so that a suitable model to describe the nonlinear stiffness of the shaft can be developed. A two supports Timoshenko beam model with two linear radial acting springs and one nonlinear rotational spring showed the best results. To get validation data for the parameter identification, we carried out an experiment that measured the force on the drive-side, the force on the operator-sided pedestal, and the discrete deflection values. The parameters of the distance between the supports and the spring were identified by minimizing the relative errors between the computed values and the measurement values. The bendline of the model and the measurement data for an external force of up to $20 \mathrm{kN}$ agree to a considerable extent. Thus, we conclude that the model succeeds in describing the nonlinear behavior of the shaft. The major cause of nonlinear stiffness behavior is the operating clearance of the two bearings at the drive-side.

In the future, further investigations must be conducted on the behavior of the shaft with equipped rolls. We will develop a simple mechanical model to describe the stiffness of a shaft with rolls. In the course of doing so, we will take into account additional parameters, such as pretension force, different rolls, and clearance, between the shaft and the rolls.

Author contributions Lamprecht: Conceptualization; methodology; data curation; software; validation; visualization; writing-original draft draft

Kocbay: Methodology; software; visualization; writing—original

Leonhartsberger: Conceptualization; data curation; writingreview and editing; validation; investigation

Vetyukov: Methodology; software; supervision; writing—review and editing

Bleicher: Writing—review and editing

Funding Open access funding provided by TU Wien (TUW).

\section{Compliance with ethical standards}

Conflict of interest The authors declare that they have no conflict of interest.

Open Access This article is licensed under a Creative Commons Attribution 4.0 International License, which permits use, sharing, adaptation, distribution and reproduction in any medium or format, as long as you give appropriate credit to the original author(s) and the source, provide a link to the Creative Commons licence, and indicate if changes were made. The images or other third party material in this article are included in the article's Creative Commons licence, unless indicated otherwise in a credit line to the material. If material is not included in the article's Creative Commons licence and your intended use is not permitted by statutory regulation or exceeds the permitted use, you will need to obtain permission directly from the copyright holder. To view a copy of this licence, visit http:// creativecommonshorg/licenses/by/4.0/.

\section{References}

1. Abeyrathna B, Rolfe B, Hodgson P, Weiss M (2016) A first step towards a simple in-line shape compensation routine for the roll forming of high strength steel. Int J Mater Form 9(3):423-434

2. Bhattacharyya D, Smith PD, Thadakamalla SK, Collins IF (1987) The prediction of roll load in cold roll-forming. J Mech Work Technol 14(3):363-379

3. Bobig P, Borsi R, Rotti M (1999) New mill stand with flexible crown control for rolling ultra-thin hot strip. Metall Plant Technol Int(Germany) 22(3):100-102

4. Ginzburg VB, Azzam M (1996) Selection of optimum strip profile and flatness technology for rolling mills. In: In 1996 AISE spring convention. pp 215-232

5. Halmos GT (2005) Roll forming handbook. Crc Press, Boca Raton

6. Jiang ZY, Zhu HT, Tieu AK (2003) Effect of rolling parameters on cold rolling of thin strip during work roll edge contact. J Mater Process Technol 140(1-3):535-541

7. Lindgren M (2009) Experimental and computational investigation of the roll forming process. $\mathrm{PhD}$ thesis, Luleå tekniska universitet

8. Mahajan P, Abrass A, Groche P (2018) Fe simulation of roll forming of a complex profile with the aid of steady state properties. Steel Res Int 89:1700350. 5

9. Müller C (2014) Numerische Abbildung und Validierung von Beanspruchungsgroßen in Rollprofilierprozessen. PhD thesis, TU Darmstadt

10. Najafabadi HM, Naeini HM, Safdarian R, Kasaei MM, Akbari D, Abbaszadeh B (2019) Effect of forming parameters on edge wrinkling in cold roll forming of wide profiles. Int J Adv Manuf Tech 101(1-4):181-194

11. Paralikas J, Salonitis K, Chryssolouris G (2009) Investigation of the effects of main roll-forming process parameters on quality for a v-section profile from ahss. Int J Adv Manuf Tech 44(3-4):223237

12. Rossi B, Degée H, Boman R (2013) Numerical simulation of the roll forming of thin-walled sections and evaluation of corner strength enhancement. Finite Elem Anal Des 72:13-20

13. Traub T, Chen X, Groche P (2017) Experimental and numerical investigation of the bending zone in roll forming. Int J Mech Sci 131:956-970

14. Tsang KS, Ion W, Blackwell P, English M (2017) Validation of a finite element model of the cold roll forming process on the basis of 3d geometric accuracy. Procedia Eng 207:1278-1283

15. Wang X, Yang Q, He H, Sun Y, Dong X, Liu Y (2020) Effect of work roll shifting control on edge drop for 6-hi tandem cold mills based on finite element method model. Int J Adv Manuf Tech, $1-15$

16. Wiebenga JH, Weiss M, Rolfe B, Boogaard AntoniusHvanden (2013) Product defect compensation by robust optimization of a cold roll forming process. J Mater Process Technol 213(6):978-986

Publisher's note Springer Nature remains neutral with regard to jurisdictional claims in published maps and institutional affiliations. 